Review

\title{
Comparative Analysis of Monitoring Devices for Particulate Content in Exhaust Gases
}

\section{Beatrice Castellani $^{1, *}$, Elena Morini ${ }^{2, \dagger}$, Mirko Filipponi ${ }^{2, \dagger}$, Andrea Nicolini ${ }^{2, \dagger}$,} Massimo Palombo ${ }^{2, \dagger}$, Franco Cotana ${ }^{2, \dagger}$ and Federico Rossi ${ }^{2}$

1 Consorzio IPASS Scarl, Via G. Guerra 23, 06127, Perugia, Italy

2 CIRIAF, University of Perugia, Via G. Duranti 67, 06125, Perugia, Italy; E-Mails: morini@crbnet.it (E.M.); filipponi.unipg@ciriaf.it (M.F.); nicolini.unipg@ciriaf.it (A.N.); massipal@libero.it (M.P.); cotana@crbnet.it (F.C.); federico.rossi@unipg.it (F.R.)

$\dagger$ These authors contributed equally to this work.

* Author to whom correspondence should be addressed; E-Mail: castellani@ipassnet.it; Tel.: +39-075-505-1704.

Received: 3 June 2014; in revised form: 1 July 2014 / Accepted: 2 July 2014 /

Published: 11 July 2014

\begin{abstract}
The installation and operation of continuous particulate emission monitors in industrial processes has become well developed and common practice in industrial stacks and ducts over the past 30 years, reflecting regulatory monitoring requirements. Continuous emissions monitoring equipment is installed not only for regulatory compliance, but also for the monitoring of plant performance, calculation of emissions inventories and compilation of environmental impact assessments. Particulate matter (PM) entrained in flue gases is produced by the combustion of fuels or wastes. The size and quantity of particles released depends on the type of fuel and the design of the plant. The present work provides an overview of the main industrial emission sources, a description of the main types of monitoring systems offered by manufacturers and a comparative analysis of the currently available technologies for measuring dust releases to atmosphere.
\end{abstract}

Keywords: particulate matter; dust; continuous emission monitoring systems; emission monitoring 


\section{Introduction}

Over the past century, scientists and environmental regulators have focused on particulate matter (PM) as one of the major areas of air pollution study and control.

Particulate matter is released as particles and includes ash, dust or rapidly agglomerating aerosols from various industrial processes via stack emissions to air [1]. The main sources of particulate include the combustion of coal, oil, gasoline/petrol, diesel, wood, biomass and high temperature industrial processes, such as smelters and steel mills.

The composition of particulate matter is highly variable and may include substances such as sulfates, nitrates, hydrogen ions, ammonium, elemental carbon, silica, alumina, organic compounds, trace elements, trace metals, particle bound water and biogenic organic species [2].

The subject of particulate continuous emission monitoring to satisfy regulatory requirements is of relatively new interest as a result of recent changes in legislation. With the advent of emission limits defined in terms of mass concentration (expressed in $\mathrm{mg} / \mathrm{m}^{3}$ ), instead of in terms of color or opacity as in the past, the issue of continuous particulate monitoring has become a new and growing regulatory requirement [3].

Operators of industrial stacks use continuous particulate monitoring instrumentation for a variety of process and environmental purposes: (i) to provide better feedback on a process, (ii) to provide continuous control, (iii) to satisfy environmental legislation. Therefore, particulate emission monitoring can be categorized by the quality and type of information provided.

Gross failure detection or broken bag detection is the simplest form of particulate monitoring since it is just a qualitative monitoring. An alarm is activated to detect a significant increase of particulate loading, indicating a filter failure. Instruments used for filter failure detection do not necessarily need to be accurate, nor have the sensitivity to measure dust levels in normal conditions. In these cases, there is no regulatory need to calibrate the instrument since the output is in terms of a relative dust output rather than an absolute level. Units of measurement are usually a percentage of full scale or a factor of normal emissions [4].

For concentration measurements in $\mathrm{mg} / \mathrm{m}^{3}$ aimed at assessing the compliance with the relevant directives, the absolute level of particulate is the issue of critical importance and the instrument must provide a calibrated output on a continuous basis. Calibration gives in situ continuous emission monitors the ability to monitor particulate in absolute terms. It consists of isokinetic or gravimetric sampling in which a sample of flue gas is collected and weighed.

Particulate emission monitoring is a challenging technical field, not only because of the specific accuracy and performance of particulate monitors, but also due to the harsh environment in which they must continuously operate.

Several studies available in literature focus on in-field tests of commercially available particulate matter continuous emission monitoring systems (PM CEMS) in industrial applications. Since the adoption of a technology should be driven by its effectiveness and value in the targeted application, the aim of the present paper is to provide a comparative analysis of the currently available technologies for measuring particulate releases to atmosphere. To do this, after a description of the relevant legislation, an overview of the main industrial stationary sources and a description of the main types of sampling systems offered by manufacturers are presented. The techniques most commonly used 
for particulate monitoring are opacity, dynamic opacity, light scattering, beta attenuation, triboelectric and electrodynamic.

\section{Relevant Legislation}

In this paragraph, the relevant European Directives and Legislation as well as technical standards are reported.

The three core EU Directives affecting industrial processes are:

- the Large Combustion Plant Directive (LCPD) 2001/80/EC which regulates large power plant, oil refineries and boiler plant on large industrial complexes;

- the Waste Incineration Directive (WID) 2000/76/EC, with relevance to incineration processes and processes that use waste as a fuel source; this covers cement kilns, some metallurgical processes and some renewable energy plant.

- the IPPC or Integrated Pollution Prevention and Control, which provides a framework for regulating chemicals, metals and minerals processes as well as defined permits for combustion and incineration plant.

The proposed Industrial Emissions Directive would consolidate these distinct requirements in a single piece of European legislation. Emission limits and monitoring requirements are defined directly in the Directives or derived from the framework defined in the industry specific BREF (Best Available Technique Reference) documents and country specific interpretation of BREF notes which are written to support the IPPC directive.

In Europe, processes falling under the Waste Incineration Directive (WID) and Large Combustion Plant Directive (LCPD) must continuously monitor particulate emissions in $\mathrm{mg} / \mathrm{m}^{3}$ in compliance with the European Standard EN 14181. The instruments are calibrated by comparison to a reference isokinetic sampling method in compliance with EN 13284 part 1 or ISO 9096.

Relevant technical standards for particulate emissions monitoring are shown in Table 1.

Table 1. Technical standards for particulate emissions monitoring.

\begin{tabular}{ll}
\hline Standard & \multicolumn{1}{c}{ Content } \\
\hline DIN EN 13284-1 & $\begin{array}{l}\text { Stationary source emissions-Determination of low range mass concentration of } \\
\text { dust-Part 1: Manual gravimetric method }\end{array}$ \\
\hline DIN EN 13284-2 & $\begin{array}{l}\text { Stationary source emissions - Determination of low range mass concentration of } \\
\text { dust-Part 2: Automated measuring systems }\end{array}$ \\
\hline DIN EN 14181 & Stationary source emissions-Quality assurance of automated measuring systems \\
\hline ISO 23210 & $\begin{array}{l}\text { Stationary source emissions-Determination of PM10/PM2,5 mass concentration in } \\
\text { flue gas-Measurement at low concentrations by use of impactors }\end{array}$ \\
\hline ISO 9096 & $\begin{array}{l}\text { Stationary source emissions-Manual determination of mass concentration of } \\
\text { particulate matter }\end{array}$ \\
\hline
\end{tabular}

\section{Overview of Stationary Emission Sources}

Major stationary sources, such as electric power plants, oil processing plants, cement production plants, and municipal waste combustors, pose several environmental problems, also in terms of dust 
emission. In addition, continuous monitoring systems at these sources often work in arduous operating conditions. This fact makes it important to understand the nature and concentration of the emitted dust.

Therefore, this paragraph provides an overview of the main stationary industrial emission sources and a description of emitted particulate matter features. In terms of particulate emissions, one of the most problematic processes in the petroleum refining chain is the fluid catalytic cracking (FCC) of heavier fractions, because of their higher hetero-atom concentration, metal contents and coking tendency. Fluid catalytic cracking (FCC) is used in the oil refining industry to convert heavy fractions to lighter products. Several process and catalyst innovations have been made to tackle the above-mentioned problems. A new generation of FCC catalyst technology has emerged with tailor-made catalysts for higher structural stability and attrition strength, more complete $\mathrm{CO}$ combustion during regeneration, reducing $\mathrm{SO}_{\mathrm{x}}$ emissions from $\mathrm{FCC}$ stacks $[5,6]$.

Loss of catalyst is a major source of dust emission in FCC sections. The catalyst used in the FCC process is produced in the form of fine powder usually below $180 \mu \mathrm{m}$. It comprises of 5\%-40\% zeolite in a matrix of alumina, semisynthetic clay derived gel or natural clay [7]. In their study of the microstructure of FCC, Bass and Ritter [8] described in great detail the chemical composition and morphology of recently developed catalysts, which are a combination of gel, clay and zeolite.

Loss of catalyst powder has been receiving attention for highly abrasive dust emissions [9-12]. The highly abrasive dust produced in FCC is critical for the installation of proper continuous emission monitoring systems. Data on particulate monitoring systems in FCC units are given by Antwerp Total Refinery [13].

At the Antwerp Total Refinery, both FCC units are operating in partial combustion mode. Part of the coke remains on the catalyst and therefore it is burned and partially converted into $\mathrm{CO}_{2}$ and $\mathrm{CO}$. CO-rich gas passes via cyclones to a downstream boiler where the combustion is completed, generating high pressure steam.

Before 2005, catalyst particles passed the CO boiler unchanged and were emitted via stack to the environment. Since 2005, an electrostatic precipitator (ESP) has been removing the majority of these particles.

For the installation of the ESPs, the refinery installed a PM CEMS for ESP monitoring and legal compliance. The installed PM CEMS was provided by Sick/Maihak (Germany), type FW56-I-Ex. The measurement principle is based on light absorption.

To avoid dust abrasion and deposits, PM CEMS was supplied with flushing air to keep the optical parts free. Since this aspect was proven critical, the system was modified. Currently, air supply to the mirror is independent from that to the transmitter/receiver and each one is equipped with its own flow indicator [13].

The use of advanced duct monitoring technologies is a high priority also for operators of waste incinerators and much data on the application of PM CEMS for compliance with the particulate emission standard of waste combustors can be found in the literature.

Eli Lilly and Company conducted a demonstration of commercially available PM CEMS on a liquid hazardous waste incinerator at Lilly's Clinton Labs in Clinton, Indiana. The objective of this demonstration was to evaluate the performance and reliability of PM CEMS in a moisture-saturated flue gas over several months of operation [14]. 
The company had the primary objective of determining how to make instrumentation work accurately in their applications. Technical concerns were primarily related to application in a wet flue gas [15]. The two instruments used in this test were the Sigrist (model KTNRM/SIGAR 4000) and the Groupe Environment S. A. (ESA) Model Beta 5M.

Results showed that the selected PM CEMS required significant, unit-specific operation and development time in order to achieve acceptable calibration. The initial failure of the ESA unit to operate properly supported the need for an initial break-in period. The endurance data for the ESA and Sigrist units were encouraging. Uptime of the ESA and Sigrist monitors were near or above the suggested requirements [15].

Another field study to evaluate the performance of three commercially available PM CEMS was conducted at the US Department of Energy (DOE) Toxic Substances Control Act (TSCA) Incinerator [16]. The three monitors were Durag F-904 K beta monitor, The Environment SA Beta 5M (ESA) and Sigrist CTNR extractive light-scattering monitor.

Several important conclusions were drawn from the results of this field study. The light scattering device required only minor maintenance and operated trouble-free throughout the study, while the beta gauge monitors had several operational problems and required a more rigorous maintenance. The beta gauge that reported emissions on a dry basis was particularly hampered with problems arising from condensation formation. Results from this test however establish the suitability of beta gauge technology for monitoring PM emissions from incinerators [16].

Other types of stationary emission sources are stacks attached to the raw mill, rotary kiln, coal mill, grate cooler, cement mill in a cement plant [17].

Majority of particulates emitted from cement industry may range from 0.05 to $5.0 \mu \mathrm{m}$ in diameter [18]. In both wet and dry process plants with dust control technology, about $85 \%$ of escaping particles were less than $10 \mu \mathrm{m}$ in diameter, while in dry plants having bag houses, about $45 \%$ of escaping particles was of $2.5 \mu \mathrm{m}$ diameter [19,20]. The particulate matter contains elemental content $\left(\mathrm{Ca}_{2}{ }^{+}, \mathrm{NO}_{3}{ }^{-}, \mathrm{SO}_{4}{ }^{2-}\right.$, $\mathrm{As}, \mathrm{Cd}, \mathrm{Co}, \mathrm{Cr}, \mathrm{Cu}, \mathrm{Fe}, \mathrm{Mn}, \mathrm{Ni}, \mathrm{Pb}$ and $\mathrm{Zn}$ ) of the principal raw materials, products, combustion material from the kiln stack in a cement plant [21]. Among the elements of environmental concern (As, $\mathrm{Cd}, \mathrm{Cr}, \mathrm{Ni}, \mathrm{Pb}$ ), As, $\mathrm{Cd}$ and $\mathrm{Pb}$ showed higher concentration in stack emitted particles [21]. Another noteworthy characteristic of the aerosol from cement plants is that its size distribution is very stable [20].

In the steel industry, PM CEMS have been used for providing qualitative information on the operation and maintenance of filter bags, but not so much for the quantitative estimation of emissions [22]. These plants are considered major sources of PM 10 and PM 2.5 emissions. A significant reduction of particulate emissions of sinter plants, until $5 \mathrm{mg} / \mathrm{Nm}^{3}$, can be achieved by fabric filters on a continuing basis [23].

There are studies in the literature for testing the applicability of continuous PM CEMS for quantitative evaluation of steel plants' emissions. In [22] different continuous emission monitoring systems for PM were compared in field conditions at a steel melting shop. The tests were performed using four commercially available monitoring instruments based on probe electrification and light scattering. Results of the tests showed that the compared instruments were not suitable for the quantitative estimation of dust emissions in widely varying field conditions. Another problem concerning the use of these monitors in quantitative measurement of emissions was the calibration of continuous PM concentration monitors. PM concentrations below $2 \mathrm{mg} / \mathrm{m}^{3}$, which predominate in the steel melting shop for most of the time, cannot be measured very reliably [22]. 
Coal combustion has been recognized as one of the major sources of fine particulates. Morphological analysis shows that the PM from pulverized coal-fired plant is composed of regular, spherical particles. In contrast, PM from circulating fluidized bed plants consists of particles of various shapes, including agglomerates of spherical, flake-like and floccus-like particles [24].

Particulate emissions from coal-fired power stations with high efficiency ESPs result in concentration lower than $100 \mathrm{mg} / \mathrm{m}^{3}$. The size distribution shows that PM 50 constitute $54.7 \%$ of total dust, while PM 10 and PM 2.5 respectively 19.9\% and 1.3\% [25].

As far as biomass combustion plants are concerned, it has been shown that small combustion boilers for district heating have considerably lower emission values than limits in regulations [26,27].

Cyclones and ESP (in larger installations) are used as abatement technologies. It is interesting that emissions are highest for the medium sized boilers [26]. While smaller boilers $(<2 \mathrm{MW})$ use multi-cyclones only, larger boilers ( $>2 \mathrm{MW}$ ) have to apply ESP to meet the emission limit value $\left(50 \mathrm{mg} / \mathrm{Nm}^{3}\right.$ for boilers $\left.>2 \mathrm{MW}\right)$. Low emission values of the smallest boilers are most likely because only wood chips are used as fuels, compared to saw dust and wood wastes in medium sized boilers.

Concerning the split of the size category $350 \mathrm{~kW}-2 \mathrm{MW}$ it can be seen that the average values for boilers in the category $350 \mathrm{~kW}$ to $1 \mathrm{MW}$ are approximately $10 \mathrm{mg} / \mathrm{Nm}^{3}$ lower than those of the category 1 to 2 MW [26]. Data on PM emissions of the analyzed stationary sources are summarized in Table 2.

Table 2. Data on emissions of major stationary sources.

\begin{tabular}{|c|c|c|c|c|}
\hline Process & PM size and concentration & PM composition & PM CEMS & References \\
\hline $\begin{array}{l}\mathrm{FCC}- \\
\text { refinery }\end{array}$ & $\sim 180 \mu \mathrm{m}$ & $\begin{array}{l}5 \%-40 \% \text { zeolite in a } \\
\text { matrix of alumina (highly } \\
\text { abrasive) }\end{array}$ & $\begin{array}{l}\text { light absorption (critical aspect } \\
\text { related to dust abrasion and } \\
\text { deposits on optics) }\end{array}$ & {$[7,8,13]$} \\
\hline $\begin{array}{l}\text { Cement } \\
\text { plants }\end{array}$ & $0.05-5.0 \mu \mathrm{m}$ & $\begin{array}{l}\text { Elemental content }\left(\mathrm{Ca}^{2+},\right. \\
\mathrm{NO}_{3}^{-}, \mathrm{SO}_{4}{ }^{2-}, \mathrm{As}, \mathrm{Cd}, \mathrm{Co}, \\
\mathrm{Cr}, \mathrm{Cu}, \mathrm{Fe}, \mathrm{Mn}, \mathrm{Ni}, \mathrm{Pb}, \mathrm{Zn}) \\
\text { Elements of } \\
\text { environmental concern } \\
(\mathrm{As}, \mathrm{Cd}, \mathrm{Cr}, \mathrm{Ni}, \mathrm{Pb})\end{array}$ & $\begin{array}{l}\text { probe electrification and } \\
\text { light scattering (problems } \\
\text { with calibration for } \\
\text { concentration below } \\
2 \mathrm{mg} / \mathrm{m}^{3} \text { ) }\end{array}$ & {$[18,21,22]$} \\
\hline $\begin{array}{l}\text { Coal } \\
\text { combustion }\end{array}$ & $\begin{array}{l}\text { PM } 50(54.7 \%) \\
\text { PM } 10(19.9 \%) \\
\text { PM } 2.5(1.3 \%)\end{array}$ & $\begin{array}{l}\text { pulverized coal-fired plant: } \\
\text { regular, spherical particles } \\
\text { circulating fluidized bed } \\
\text { plants: agglomerates of } \\
\text { spherical, flake-like and } \\
\text { floccus-like particles }\end{array}$ & - & {$[24,25]$} \\
\hline $\begin{array}{l}\text { Biomass } \\
\text { combustion }\end{array}$ & $\begin{array}{l}\text { 0-100 kW: } 14.4 \mathrm{mg} / \mathrm{Nm}^{3} \\
\text { 100-350 kW: } 34.8 \mathrm{mg} / \mathrm{Nm}^{3} \\
350 \mathrm{~kW}-1 \mathrm{MW}: 57.5 \mathrm{mg} / \mathrm{Nm}^{3} \\
1 \mathrm{MW}-2 \mathrm{MW}: 67.0 \mathrm{mg} / \mathrm{Nm}^{3} \\
350-2.000 \mathrm{~kW}: 61.2 \mathrm{mg} / \mathrm{Nm}^{3} \\
2-5 \mathrm{MW}: 9.4 \mathrm{mg} / \mathrm{Nm}^{3} \\
>5 \mathrm{MW}: 10.9 \mathrm{mg} / \mathrm{Nm}^{3}\end{array}$ & - & - & {$[26]$} \\
\hline
\end{tabular}




\section{Particulate Matter Continuous Emission Monitoring Technologies}

The main analytical principles used in instruments to measure dust concentrations are described below. These principles are opacity, light scattering, beta attenuation, probe electrification (triboelectric effect, electrodynamic device).

PM CEMS based on such technologies must be calibrated by gravimetric and isokinetic sampling to provide a continuous output of dust concentration in $\mathrm{mg} / \mathrm{m}^{3}$. In fact, gravimetric sampling is the only method that gives real concentration. Gravimetric measurement consists in taking off a partial gas flow via a filter head probe. The dust content is determined by weighting the dust collector mass before and after extraction. Gravimetric sampling is carried out isokinetically: it means that the collected particles have the same velocity in the sampling nozzle as elsewhere in the stream. This increases the accuracy and reliability of results.

\subsection{Opacity}

Opacity meters measure the decrease in light intensity due to absorption and scattering as the beam crosses the stack according to Beers-Lambert's Law. The basic operational principle of these instruments is that a collimated beam of visible light is directed through a gas stream toward receiving optics (Figure 1). The receiving optics measure the decrease in light intensity, and the instrument electronics convert the signal to an instrument output. Technical description of commercial opacity meters is given in Table 3. These instruments measure smoke density in transmission, opacity, Ringelmann units or optical density (extinction) and/or mass concentration of particulate in $\mathrm{mg} / \mathrm{Nm}^{3}$ [28].

Figure 1. Opacity measurement setup [29].

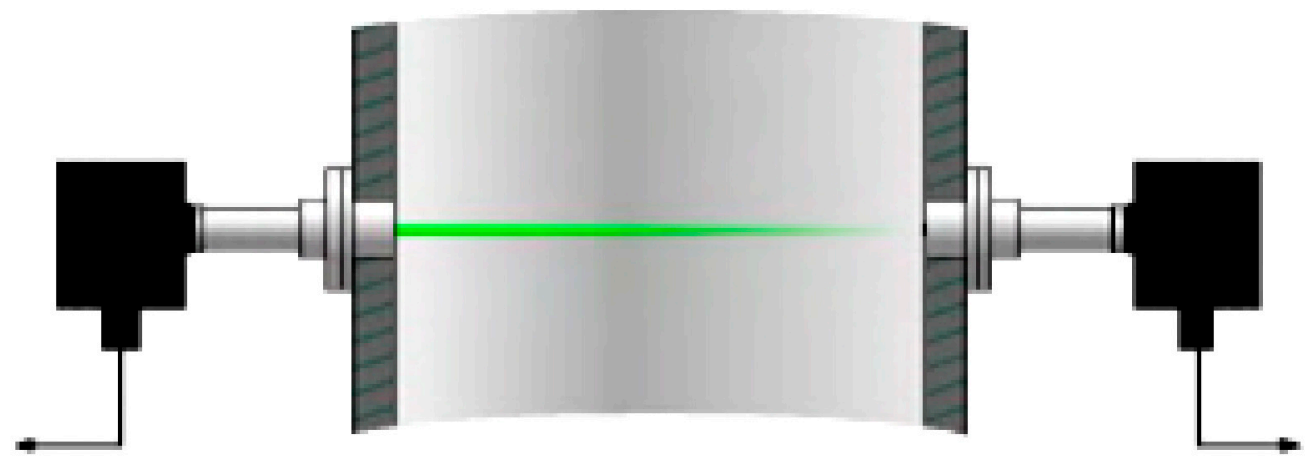

The intensity of the light at the detector, $\mathrm{I}$, is compared with the reference light intensity, $\mathrm{I}_{\mathrm{o}}$, to give the transmittance T, as shown in Equation (1):

$$
T=\frac{I}{I_{0}}
$$


Transmittance can be converted to opacity Op (Equation (2)) or optical density D (Equation (3)):

$$
\begin{gathered}
O p=1-T \\
D=\log \left(\frac{1}{T}\right)
\end{gathered}
$$

The loss of light intensity can be correlated to particulate mass concentration measured by manual gravimetric sampling.

There are two formats for opacity devices. Single path monitors simply project a beam across a duct to a receiver. Dual beam devices have a reflector mirror on the opposite side of the stack from the light source and the beam is projected between two transceivers. This enables each transceiver to compensate for gradual window contamination by using clean mirrors inserted periodically into the beam path. In this way, any errors caused by misalignment of the sensors may be compensated for.

The dual-pass opacity meter allows all the instrument electronics to be incorporated into one unit. Incorporating the light source and detector into one instrument also allows direct measurement of the loss of light. In fact, the source intensity and the loss of light are measured and compared at the same time. This helps prevent inaccurate readings due to the degradation of the light source intensity that is a common problem in basic meters.

A opacity meter used as PM CEMS should use a red or near infrared light source, and not the white light source used on traditional opacity monitors since the extinction-to-mass concentration for a given aerosol type is dependent on particle size within the visible light spectrum but nearly independent of particle size at the infrared wavelength. Some manufacturers have started using a green LED to monitor both opacity and PM concentration simultaneously [30].

Opacity measurements are dependent on particle size, composition, shape, color and refractive index. These properties may change with fuel type and thus calibration is necessary with variation of process conditions [31,32]. In general, the measurement sensitivity of opacity meters is not fine enough to detect small changes in PM concentration.

An alternative type of cross stack optical dust monitor is the dynamic opacity device. While traditional opacity instruments measure the intensity of received light, the dynamic opacity technology instead measures the ratio of signal scintillation to absolute light intensity. This offers a significant advantage over traditional opacity methods, as the ratiometric measurement is unaffected by lens contamination allowing the instrument to operate with lens contamination exceeding $90 \%$. In fact, since both the reduction in light intensity and the variation in intensity caused by lens contamination are affected by the same proportion, it results in no net effect. This therefore greatly reduces costly process intervention for lens maintenance and servicing.

The dynamic opacity device is suitable for stacks after bag filters, cartridge filters, cyclones, electrostatic precipitators, variable flue gas velocities, including low velocity flue gases, variable particulate size and type [29]. 
Table 3. Technical data of commercial opacity meters [33-36].

\begin{tabular}{|c|c|c|c|c|c|c|}
\hline Model & STACK 602 & DR 290 & DR 220 & LAND 4200 & LAND 4500 III & $\begin{array}{l}\text { DUSTHUNTER } \\
\text { T200 }\end{array}$ \\
\hline Measurement & Ratiometric opacity technology & $\begin{array}{l}\text { Optical transmission of } \\
\text { visible light }\end{array}$ & $\begin{array}{l}\text { Optical transmission } \\
\text { of visible light }\end{array}$ & Path transmissometry & Path transmissometry & $\begin{array}{l}\text { Transmittance } \\
\text { measurement }\end{array}$ \\
\hline Sensors & Cross-stack & Double pass & Double pass & Double pass & Cross stack, double pass & Cross-duct \\
\hline Light Source & Modulated LED (green spectrum) & $\begin{array}{l}\text { Wide Band } \\
\text { Diode-White } \\
\text { SWBD LED white, } \\
450-680 \mathrm{~nm}\end{array}$ & LED, green $530 \mathrm{~nm}$ & $\begin{array}{l}\text { High intensity LED } \\
\text { red } 623 \pm 20 \mathrm{~nm}\end{array}$ & $\begin{array}{l}\text { High Intensity LED } \\
\text { Green } 520 \pm 20 \mathrm{~nm}\end{array}$ & Not available \\
\hline $\begin{array}{l}\text { Duct/stack } \\
\text { diameter }\end{array}$ & $1-15 \mathrm{~m}$ & $1-18 \mathrm{~m}$ & $0.4-15 \mathrm{~m}$ & $0.3-9.7 \mathrm{~m}$ & $0.5-10 \mathrm{~m}$ & $0.5-12 \mathrm{~m}$ \\
\hline $\begin{array}{l}\text { Max } \\
\text { Temperature } \\
\text { flue gas }\end{array}$ & $600^{\circ} \mathrm{C}$ & $600^{\circ} \mathrm{C}$ & $600{ }^{\circ} \mathrm{C}$ & $600{ }^{\circ} \mathrm{C}$ & $600{ }^{\circ} \mathrm{C}$ & $600^{\circ} \mathrm{C}$ \\
\hline $\begin{array}{l}\text { Measurement } \\
\text { range }\end{array}$ & $10-1,000 \mathrm{mg} / \mathrm{m}^{3}$ & $\begin{array}{l}0.5-15 / \\
500-10,000 \mathrm{mg} / \mathrm{m}^{3}\end{array}$ & $2-10,000 \mathrm{mg} / \mathrm{m}^{3}$ & $0-100 / 0-999 \mathrm{mg} / \mathrm{m}^{3}$ & $\begin{array}{l}0-10 / \\
0-10,000 \mathrm{mg} / \mathrm{m}^{3}\end{array}$ & $\begin{array}{l}0-200 / \\
0-10,000 \mathrm{mg} / \mathrm{m}^{3}\end{array}$ \\
\hline $\begin{array}{l}\text { Standard } \\
\text { Compliance }\end{array}$ & $\begin{array}{l}\text { EN } 14181 \\
\text { EN 13284-2 }\end{array}$ & $\begin{array}{l}\text { EN } 13284-2 \\
\text { EN } 14181 \\
\text { EN } 15267-3\end{array}$ & & & $\begin{array}{l}\text { EN 15267-1 } \\
\text { EN 15267-2 } \\
\text { EN 15267-3 } \\
\text { EN } 14181\end{array}$ & $\begin{array}{l}\text { EN } 14181 \\
\text { EN 15267-3 }\end{array}$ \\
\hline Comments & $\begin{array}{l}\text { applications with electrostatic } \\
\text { precipitator } \\
\text { large diameter emission stacks } \\
\text { variable flue gas velocities, including } \\
\text { low velocity flue gases } \\
\text { variable particulate size and type }\end{array}$ & $\begin{array}{l}\text { suitable for systems with } \\
\text { variable gas speed } \\
\text { super-wide band diode } \\
\text { (SWBD) reduces influence } \\
\text { of variable particle sizes }\end{array}$ & $\begin{array}{l}\text { filter monitoring } \\
\text { suitable for } \\
\text { applications with } \\
\text { variable gas speed }\end{array}$ & $\begin{array}{l}\text { process/ } \\
\text { non-compliance } \\
\text { performance reduced } \\
\text { for pathlengths }>7.5 \mathrm{~m}\end{array}$ & & $\begin{array}{l}\text { measurement } \\
\text { independent of gas } \\
\text { velocity, humidity } \\
\text { and particle charge }\end{array}$ \\
\hline
\end{tabular}




\subsection{Light Scattering}

Scattering is due to reflection and refraction of the light by the particle. The amount of light scattered is based on the concentration of particles and the properties of the particles in the light's path (e.g., size, shape, and color of the particles) [37,38]. If the wavelength of the incident light is much larger than the radius of the particle, a type of scattering called Rayleigh scattering occurs. If the wavelength of the incident light is about the same size as the radius of the particle, Mie scattering will occur (Figure 2).

Figure 2. Mie and Rayleigh scattering.

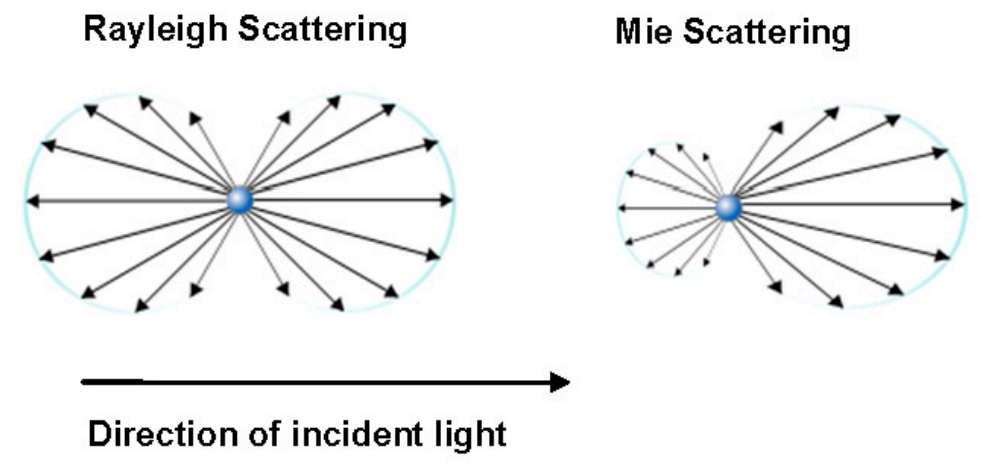

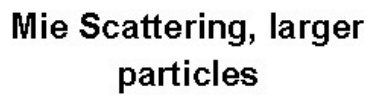

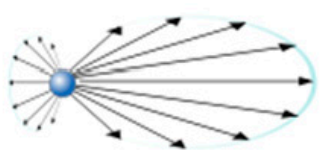

A light scatter instrument measures the amount of light scattered in a particular direction (forward, side, or backward) and outputs a signal proportional to the amount of particulate matter in the stream. The dust concentration is derived by correlating the output of the instrument to manual gravimetric measurements [4].

Some components included in these instruments to minimize the effect of interference and degradation of the light source are: (i) the use of a pulsed light and (ii) parallel measurement of the light source intensity. The use of the pulsed light source limits the possibility of other sources' interference, because the instrument only measures the reflected light while the instrument light source is on. The parallel measurement of the light source intensity accounts for degradation of the light source because a reference of the source intensity is measured along with each scattered light measurement.

For scattered light measurements, back and forward scattering are used. They are shown in Figure 3. Back scatter devices are particularly suitable for in situ applications in small ducts, where low levels of dust are present. Low angle of back scatter measurement increases the effective penetration of the measurement volume into the stack but makes the instrument less sensitive to fine dust.

There are three types of forward scatter devices available currently: (i) the extractive type, (ii) probe configuration and (iii) cross duct configuration.

The extractive type draws a sample from the stack via a sampling nozzle and then presents it to a forward scattering photometer. The advantage of this system is the ability to heat the sampling system, where there are significant amounts of moisture in the stack. The sensor measures the amount of light scattered back from particles in the stack illuminated by a modulated laser [36]. 
Figure 3. Light-scattering configurations: (a) backward scattering (b) probe forward scattering (c) cross forward scattering [36].

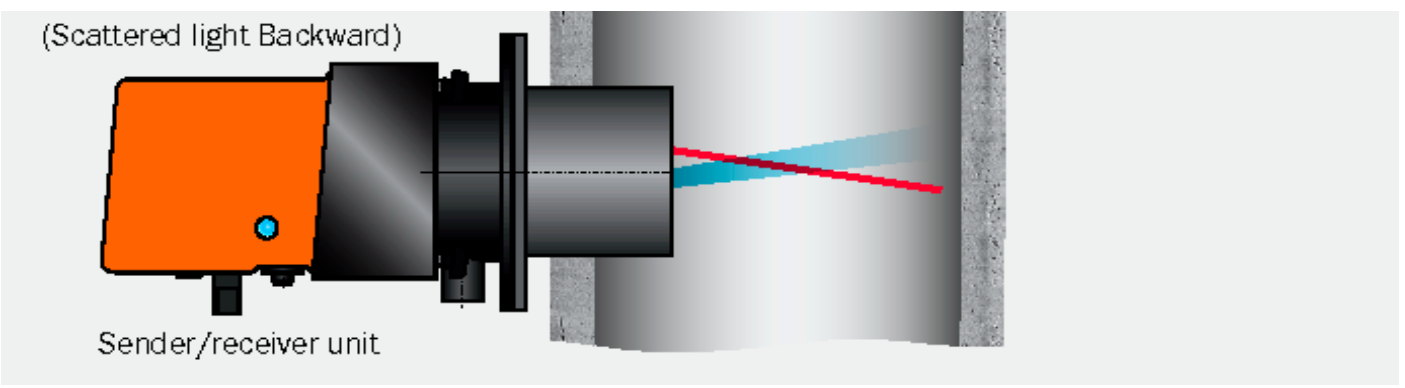

(a)

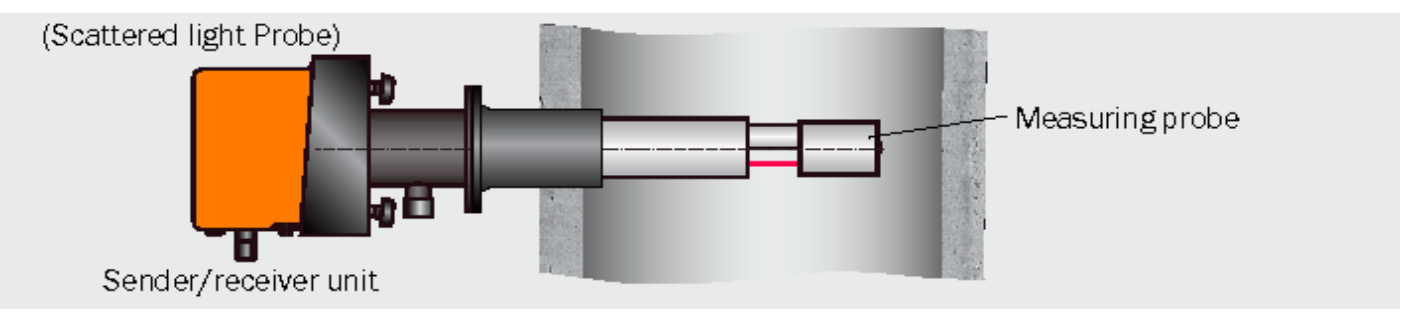

(b)

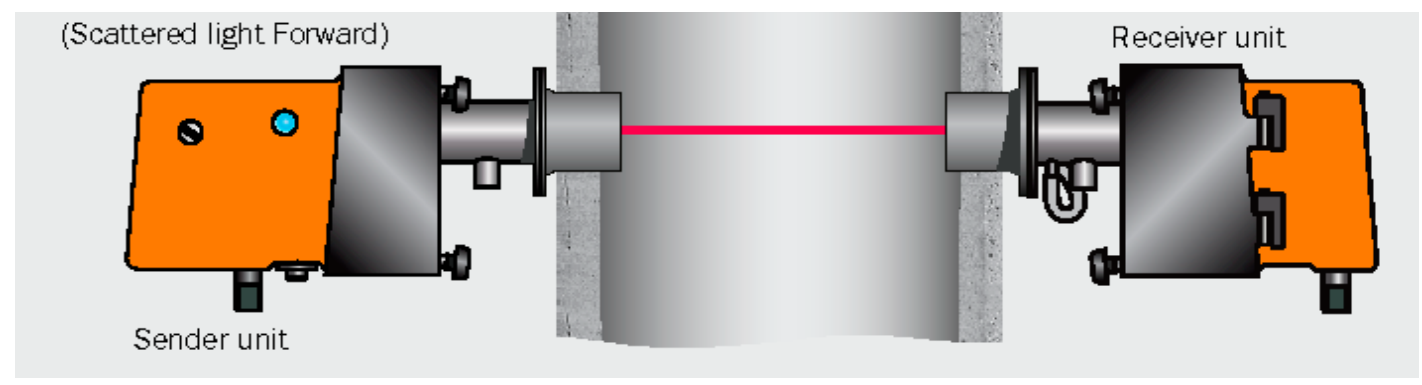

(c)

The probe forward scatter instrument has a measurement volume at the tip of a probe and measures the light scattered at a forward angle to the incident beam (typically coming from a laser diode). If the instrument is located in a representative position, it can provide high accuracy measurement in a variety of low and high dust applications.

The cross duct forward scatter instrument has a transmitter and a receiver opposite each other on the stack. A diode laser projects a beam of light into the stack: part of the beam is attenuated and some is scattered by the particulate. The receiver has a large lens behind which are two photo-detectors, the nearer lens detects a transmission signal and the further, the scattered component.

Compared to forward scatter cross stack designs, probe forward scatter provides a representative measurement without the errors deriving from misalignment, vibration, near wall measurement sensitivity and the complexity of keeping a double head system clean. In addition, cross stack scatter has a varying response to dust along its measurement path [4].

A technical description of commercial light scattering meters is given in Table 4. 
Table 4. Technical data of commercial light scattering meters [33,34,36,39].

\begin{tabular}{|c|c|c|c|c|c|c|c|c|c|c|}
\hline Model & STACK 181 & DR 300-40 & DR 800 & SB50 & SB100 & $\mathrm{C} 200$ & SF100 & SP100 & FEW 200 & $\begin{array}{l}\text { SIGRIST } \\
\text { STACKGU } \\
\text { ARD } \\
\end{array}$ \\
\hline Principle & $\begin{array}{l}\text { Low-angle } \\
\text { forward light } \\
\text { scattering }\end{array}$ & $\begin{array}{l}\text { Backward } \\
\text { light } \\
\text { scattering } \\
\text { (halogen lamp } \\
\text { white) }\end{array}$ & $\begin{array}{l}\text { Forward light } \\
\text { scattering } \\
\text { (laser diode, } \\
\text { red } 650 \mathrm{~nm} \text { ) }\end{array}$ & $\begin{array}{l}\text { Scattered } \\
\text { light } \\
\text { backward }\end{array}$ & $\begin{array}{l}\text { Scattered light } \\
\text { backward laser } \\
\text { wavelength } \\
\text { between } 640 \\
\mathrm{~nm} \text { and } 660 \mathrm{~nm}\end{array}$ & $\begin{array}{l}\text { Combination of } \\
\text { transmissometry } \\
\text { and Scattered } \\
\text { light forward }\end{array}$ & $\begin{array}{l}\text { Scattered light } \\
\text { forward } \\
\text { Cross-duct } \\
\text { version }\end{array}$ & $\begin{array}{l}\text { Scattered } \\
\text { light forward } \\
\text { probe version }\end{array}$ & $\begin{array}{l}\text { Scattered } \\
\text { light forward } \\
\text { (extractive } \\
\text { type for wet } \\
\text { gases) }\end{array}$ & $\begin{array}{l}\text { Scattered light } \\
\text { (extractive } \\
\text { type) } \\
\text { wavelength } \\
650 \mathrm{~nm} \\
\end{array}$ \\
\hline $\begin{array}{l}\text { Duct/stack } \\
\text { diameter }\end{array}$ & $\begin{array}{l}250 \mathrm{~mm}-3 \mathrm{~m} \\
\text { (multi-sensor } \\
\text { configuration } \\
\text { required for } \\
\text { stack }>3 \mathrm{~m} \text { ) }\end{array}$ & $>0.3 \mathrm{~m}$ & $>0.3 \mathrm{~m}$ & $>0.5 \mathrm{~m}$ & $<0.5 \mathrm{~m}$ & $0.5-8 \mathrm{~m}$ & $\begin{array}{l}0.5-3 \mathrm{~m} \\
2.5-6 \mathrm{~m}\end{array}$ & $\geq 0.25 \mathrm{~m}$ & - & - \\
\hline $\begin{array}{l}\text { Max flue gas } \\
\text { temperature }\end{array}$ & $\begin{array}{l}250^{\circ} \mathrm{C} \text { (optional } \\
500^{\circ} \mathrm{C} \text { ) }\end{array}$ & $320^{\circ} \mathrm{C}$ & $220^{\circ} \mathrm{C}$ & $600^{\circ} \mathrm{C}$ & $600^{\circ} \mathrm{C}$ & $300^{\circ} \mathrm{C}$ & $300^{\circ} \mathrm{C}$ & $400{ }^{\circ} \mathrm{C}$ & $220^{\circ} \mathrm{C}$ & $160^{\circ} \mathrm{C}$ \\
\hline $\begin{array}{l}\text { Measurement } \\
\text { range }\end{array}$ & $\begin{array}{l}0-15 / 0-100 \\
\mathrm{mg} / \mathrm{m}^{3}\end{array}$ & $\begin{array}{l}0.5-10 / 10- \\
200 \mathrm{mg} / \mathrm{m}^{3}\end{array}$ & $\begin{array}{l}0.5-10 / 10- \\
200 \mathrm{mg} / \mathrm{m}^{3}\end{array}$ & $\begin{array}{l}0-20 / 0-200 \\
\mathrm{mg} / \mathrm{m}^{3}\end{array}$ & $\begin{array}{l}0-10 / 0-200 \\
\mathrm{mg} / \mathrm{m}^{3}\end{array}$ & $\begin{array}{l}\text { scattered light: } \\
0-5 / 0-200 \\
\mathrm{mg} / \mathrm{m}^{3} \\
\text { transmission } \\
0-200 / 0-10,000 \\
\mathrm{mg} / \mathrm{m}^{3}\end{array}$ & $\begin{array}{l}0-5 / 0-200 \\
\mathrm{mg} / \mathrm{m}^{3}\end{array}$ & $\begin{array}{l}0-5 / 0-200 \\
\mathrm{mg} / \mathrm{m}^{3}\end{array}$ & $\begin{array}{l}0-5 / 0-200 \\
\mathrm{mg} / \mathrm{m}^{3}\end{array}$ & $\begin{array}{l}0-100 \\
\mathrm{mg} / \mathrm{m}^{3} \\
\text { PLA } \\
\text { (polystyrene- } \\
\text { latex-aerosol) }\end{array}$ \\
\hline $\begin{array}{l}\text { Standard } \\
\text { Compliance }\end{array}$ & $\begin{array}{l}\text { EN } 15267-3 \\
\text { EN } 14181 \\
\text { EN ISO } 14956\end{array}$ & $\begin{array}{l}\text { EN 13284-2 } \\
\text { EN } 14181\end{array}$ & $\begin{array}{l}\text { EN 13284-2 } \\
\text { EN } 14181\end{array}$ & $\begin{array}{l}\text { EN 15267-3 } \\
\text { EN } 14181\end{array}$ & $\begin{array}{l}\text { EN 15267-3 } \\
\text { EN } 14181\end{array}$ & $\begin{array}{l}\text { EN } 15267-3 \\
\text { EN } 14181 \\
\text { DIN ISO } 14956\end{array}$ & $\begin{array}{l}\text { EN } 14181 \\
\text { EN } 15267\end{array}$ & $\begin{array}{l}\text { EN } 14181 \\
\text { EN } 15267\end{array}$ & $\begin{array}{l}\text { EN } 14181 \\
\text { EN } 15267\end{array}$ & EN 14181 \\
\hline
\end{tabular}


Table 4. Cont.

\begin{tabular}{|c|c|c|c|c|c|c|c|c|c|c|}
\hline Model & STACK 181 & DR 300-40 & DR 800 & SB50 & SB100 & $\mathrm{C200}$ & SF100 & SP100 & FEW 200 & $\begin{array}{l}\text { SIGRIST } \\
\text { STACKGU } \\
\text { ARD } \\
\end{array}$ \\
\hline Comments & $\begin{array}{l}\text { after electrostatic } \\
\text { precipitator } \\
\text { both constant } \\
\text { and variable flue } \\
\text { gas velocities } \\
\text { variable } \\
\text { particulate size }\end{array}$ & $\begin{array}{l}\text { variable stack } \\
\text { gas speed } \\
\text { low to } \\
\text { medium dust } \\
\text { concentration }\end{array}$ & $\begin{array}{l}\text { variable stack } \\
\text { gas speed } \\
\text { low to } \\
\text { medium dust } \\
\text { concentration }\end{array}$ & $\begin{array}{l}\text { low to } \\
\text { medium } \\
\text { concentration }\end{array}$ & $\begin{array}{l}\text { low to medium } \\
\text { concentration }\end{array}$ & $\begin{array}{l}\text { very low and } \\
\text { high dust } \\
\text { concentration }\end{array}$ & $\begin{array}{l}\text { very low to } \\
\text { medium dust } \\
\text { concentration } \\
\text { small to } \\
\text { medium duct } \\
\text { diameters }\end{array}$ & $\begin{array}{l}\text { very low to } \\
\text { medium dust } \\
\text { concentration } \\
\text { small to } \\
\text { medium duct } \\
\text { diameters }\end{array}$ & $\begin{array}{l}\text { very low to } \\
\text { medium dust } \\
\text { concentration } \\
\text { gas sampling } \\
\text { and return } \\
\text { combined in } \\
\text { one probe }\end{array}$ & $\begin{array}{l}\text { steam- } \\
\text { saturated and } \\
\text { corrosive } \\
\text { gases }\end{array}$ \\
\hline
\end{tabular}




\subsection{Beta Attenuation}

$\beta$-gauge samplers are the only systems which continuously measure the mass concentration of particulate by extraction. The particles are collected isokinetically on a filter tape and the change in transmission of $\beta$-particles from a radioactive source is monitored. The particulate laden gas is extracted via a small nozzle from the duct. The extraction rate is controlled by a duct flow sensing system. The captured material is placed on a constantly moving sticky tape and then presented to a $\beta$ gauge to measure the mass (Figure 4).

The two main components of a beta attenuation measuring system are the beta source, in general Carbon-14, and the detector. Many different types of detectors can quantify beta particle counts, but the ones most widely used are the Geiger Mueller counter or a photodiode detector.

Beta systems do not provide short term dynamic monitoring of particulates and a single point measurement may not always be representative. The heated isokinetic sampling train is prone to maintenance problems. Measurements are made against a reference measurement already on the tape in $\mathrm{mg} / \mathrm{m}^{3}$.

The advantage is that they are not affected by chemical composition, size or color changes in the particles, and the use of a heated probe obviates water effects. Technical description of commercial Beta attenuation meters is given in Table 5.

Figure 4. Beta attenuation for dust monitoring on stacks [40].

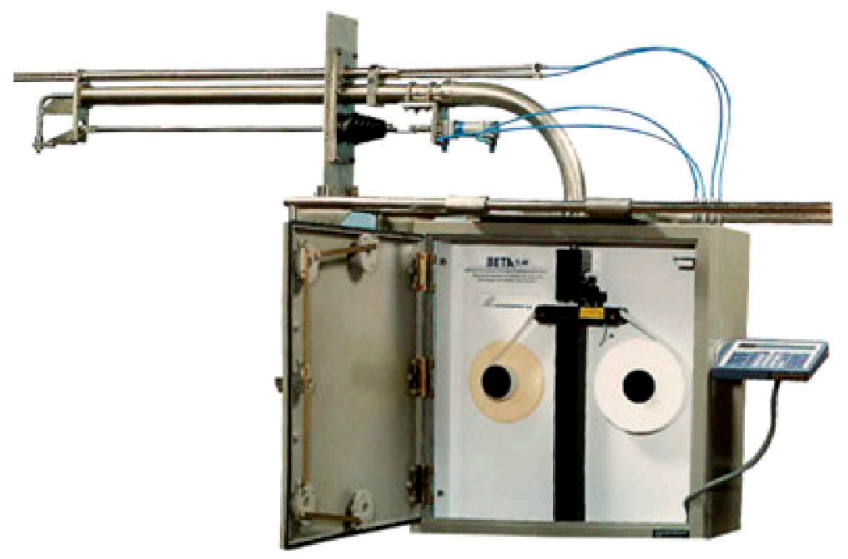

Table 5. Technical data of commercial beta attenuation meters $[34,41]$.

\begin{tabular}{lll}
\hline Model & F-904-20 & BETA 5M \\
\hline Principle & $\begin{array}{l}\text { Beta gauge measurement with Isokinetic } \\
\text { sampling }\end{array}$ & $\begin{array}{l}\text { Beta gauge measurement with Isokinetic } \\
\text { sampling }\end{array}$ \\
\hline Source & & very low activity Carbon 14 source \\
\hline $\begin{array}{l}\text { Duct/stack } \\
\text { diameter }\end{array}$ & $>0.5 \mathrm{~m}$ & - \\
\hline $\begin{array}{l}\text { Velocity } \\
\text { Max flue gas } \\
\text { temperature }\end{array}$ & $0-250{ }^{\circ} \mathrm{C}$, optional up to $500{ }^{\circ} \mathrm{C}$ & 4 to $40 \mathrm{~m} / \mathrm{s}$ \\
\hline
\end{tabular}


Table 5. Cont.

\begin{tabular}{lll}
\hline Model & F-904-20 & BETA 5M \\
\hline $\begin{array}{lll}\text { Measurement } \\
\text { range }\end{array}$ & $0-1 / 0-1000 \mathrm{mg} / \mathrm{m}^{3}$ & $2-4000 \mathrm{mg} / \mathrm{m}^{3}$ \\
\hline Standard & EN 14181 & ISO 10473 \\
Compliance & & EN 13284-2 \\
& & EN 14181 \\
& & ISO 9096 \\
\hline Comments & unaffected by particle size, color or moisture & independent of particulate characteristics \\
& measuring of very low emission dust & \\
& concentration & \\
& small diameter stack monitoring of dust & \\
& concentration & \\
\hline
\end{tabular}

\subsection{Triboelectric Effect}

Triboelectric devices (Figure 5) detect three separate effects when particulate strikes or passes close to a conductor placed in a particle laden gas stream: (i) when a particle strikes the conductor, a charge transfer takes place between particle and conductor; (ii) as the particle strikes the conductor it rubs on the surface and causes a frictional charge; (iii) as charged particles pass close to the conductor they induce a charge of equal and opposite magnitude in the conductor. The amount of charge generated by the first two effects depends on the velocity of the particle, its mass and the charge history of the particle, while the third effect is an inductive charge. The size of the charge is dependent on the proximity of the particle to the conductor and the charge history of the particle [40].

Figure 5. Probe Electrification device [33].

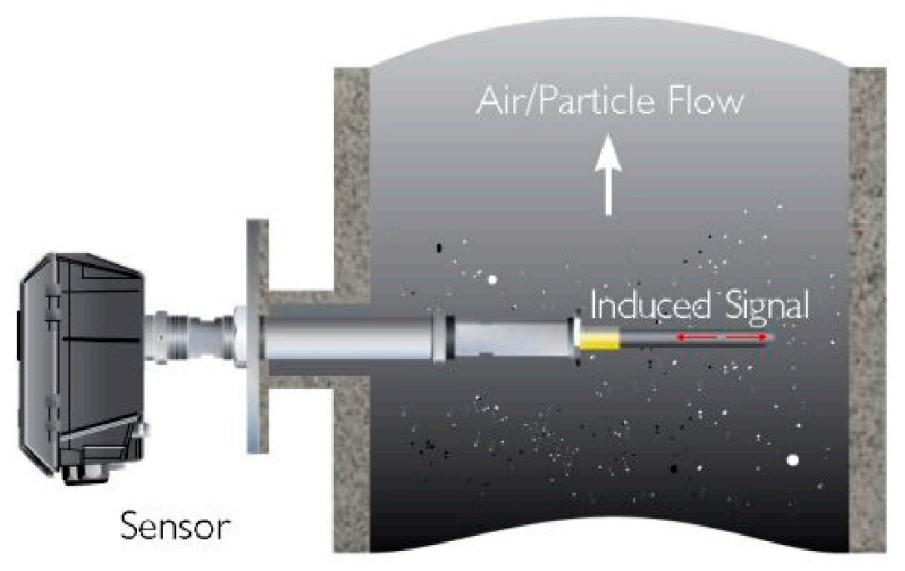

Since the response of the probe is sensitive to gas velocity, these systems are most suited to situations where the gas flow is fairly constant. Probe electrification does not work well in wet gas streams with water droplets or when the particles are subject to a varying electrical charge.

Triboelectric monitors are very sensitive to low levels of particulate concentration. They work best where the particulate material is non-conductive. Like other dust monitors, this system has to be calibrated against an extractive method at each individual site. 


\subsection{Electrodynamic Device}

Like other probe electrification devices, the sensor measures the current created by particles passing and colliding with a grounded sensor rod inserted into stack.

The sensor electronics filter out the DC current created by particle collisions on the rod and measure an RMS signal within an optimized frequency bandwidth which results from the particles passing the rod. This signal, being independent of the rod surface condition, has a stable and repeatable relationship to dust concentration in many types of industrial applications.

Since the signal is not dependent on particle collisions (unlike triboelectric) the related problems of rod contamination and velocity dependence are minimized [42]. In applications where the particle charge, particle size and particle distribution remain constant the resulting alternating current is proportional to dust concentration.

Technical description of commercial electrification devices is given in Table 6 .

Table 6. Technical data of commercial electrification devices [33,34,43].

\begin{tabular}{|c|c|c|c|c|}
\hline Model & PFM 02 V & D-RX 250 & QAL 991 & VIEW 370 \\
\hline Principle & $\begin{array}{l}\text { Measurement with } \\
\text { triboelectric sensor }\end{array}$ & $\begin{array}{l}\text { Dust: measuring the } \\
\text { transfer of electrical } \\
\text { charge from dust } \\
\text { particles to an } \\
\text { electrode in flowing } \\
\text { sample gas } \\
\text { Flow: measuring the } \\
\text { differential pressure } \\
\text { created by a multi } \\
\text { point pitot tube }\end{array}$ & $\begin{array}{l}\text { ElectroDynamic Probe } \\
\text { Electrification } \\
\text { technology }\end{array}$ & $\begin{array}{l}\text { ElectroDynamic Probe } \\
\text { Electrification } \\
\text { technology }\end{array}$ \\
\hline $\begin{array}{l}\text { Duct/stack } \\
\text { diameter }\end{array}$ & & $>0.3 \mathrm{~m}$ & $\begin{array}{l}0.5-3 \mathrm{~m} \text { (multi-sensor } \\
\text { configuration required } \\
\text { for stack }>3 \mathrm{~m} \text { ) }\end{array}$ & $0.1-6 \mathrm{~m}$ \\
\hline Flow velocity & from $3 \mathrm{~m} / \mathrm{s}$ & $7-35 \mathrm{~m} / \mathrm{s}$ & $8-20 \mathrm{~m} / \mathrm{s}$ & $8-20 \mathrm{~m} / \mathrm{s}$ \\
\hline $\begin{array}{l}\text { Max flue gas } \\
\text { temperature }\end{array}$ & $280{ }^{\circ} \mathrm{C}$ & $350^{\circ} \mathrm{C}$ & $250{ }^{\circ} \mathrm{C} / 500{ }^{\circ} \mathrm{C}$ & $800^{\circ} \mathrm{C}$ \\
\hline $\begin{array}{l}\text { Measurement } \\
\text { range }\end{array}$ & $0-10 / 0-1000 \mathrm{mg} / \mathrm{m}^{3}$ & $0-10 / 0-500 \mathrm{mg} / \mathrm{m}^{3}$ & $0-1000 \mathrm{mg} / \mathrm{m}^{3}$ & $0-500 \mathrm{mg} / \mathrm{m}^{3}$ \\
\hline Comments & & & $\begin{array}{l}\text { constant velocity } \\
\text { required outside its } \\
\text { velocity range }\end{array}$ & $\begin{array}{l}\text { constant velocity } \\
\text { required outside its } \\
\text { velocity range }\end{array}$ \\
\hline
\end{tabular}

\section{Comparison and Conclusions}

The advent of emission limits, expressed in $\mathrm{mg} / \mathrm{m}^{3}$, requires the use on industrial stacks of PM CEMS. The comparative analysis presented in this paper is driven by the fact that there are a variety of industrial processes which produce dust emissions in the environment. To satisfy legislation and industrial requirements, a full range of techniques are used in practice and provide a practical and robust solution for most industrial applications. 
The most used PM CEMS in industrial applications, in accordance with the analyzed literature papers, are light scattering devices, opacity meters and electrification devices. Extractive types such as beta gauge are less used than in situ types.

One of the fundamental issues in obtaining good results from particulate instruments is to ensure that the instrument is fit for purpose for the intended application [7-10,29]. As a result of the analysis carried out in the previous paragraph, Table 7 shows the core application areas of the different technologies.

Scattering instruments in general can measure much lower emissions than opacity instruments and are therefore suitable for processes controlled by highly efficient bagfilters [44]. Compared to backscatter, opacity and dynamic opacity systems, probe forward scattering technique may be used to accurately monitor very low dust concentrations.

As far as electrification devices are concerned, if compared to opacity systems, they do not suffer from misalignment and are suitable for measuring dust levels below $0.1 \mathrm{mg} / \mathrm{m}^{3}$. In case of particle charging by electrostatic precipitators, electrification technologies are outside their application limits and light-scattering can provide an alternative solution. A comparison of opacity, light scattering and electrification, based on stack diameter and PM concentration is given in Figure 6.

Concluding, the performance and suitability of any particulate monitor is application dependent [29]. Each type of CEMS presents disadvantages or advantages over other types of CEMS for a targeted industrial application. The choice of a PM CEMS for a plant should be driven by the correlation between operating parameters and proper technical characteristics of PM CEMS.

Table 7. Comparison of particulate monitoring technologies.

\begin{tabular}{|c|c|c|c|c|c|c|}
\hline \multirow{2}{*}{\multicolumn{2}{|c|}{ Measurement Technology }} & \multirow{3}{*}{$\begin{array}{l}\text { Stack } \\
\text { diameter (m) }\end{array}$} & \multicolumn{2}{|c|}{ Concentration $\left(\mathrm{mg} / \mathrm{m}^{3}\right)$} & \multirow{3}{*}{$\begin{array}{l}\text { Filter Type } \\
\text { Bag, Cyclone, } \\
\text { Drier, Scrubber } \\
\text { (no water droplets), } \\
\text { None }\end{array}$} & \multirow{3}{*}{$\begin{array}{l}\text { Velocity } \\
\text { dependent }\end{array}$} \\
\hline & & & Min & $\operatorname{Max}$ & & \\
\hline \multirow[t]{2}{*}{$\begin{array}{l}\text { Probe } \\
\text { Electrification }\end{array}$} & Triboelectric & & 0 & 1000 & & \\
\hline & Electrodynamic & $0.5-3$ & 0 & 1000 & Bag, Cyclone & Yes \\
\hline \multirow[t]{2}{*}{ Transmisometry } & $\begin{array}{l}\text { Ratiometric } \\
\text { Opacity }\end{array}$ & $1-15$ & 10 & 1000 & $\begin{array}{l}\text { Bag (concentration } \\
\text { dependent), } \\
\text { Cyclone, EP, None }\end{array}$ & No \\
\hline & Opacity & $0.5-18$ & 0 & 10000 & EP, None & No \\
\hline \multirow{2}{*}{ Scattered light } & Forward & $0.25-6$ & 0.1 & 200 & Bag, Cyclone, EP & No \\
\hline & Back & $0.3-4$ & 0.5 & 200 & Bag, Cyclone, EP & No \\
\hline
\end{tabular}


Figure 6. Comparison of opacity, light scattering and electrification: stack diameter and concentration.

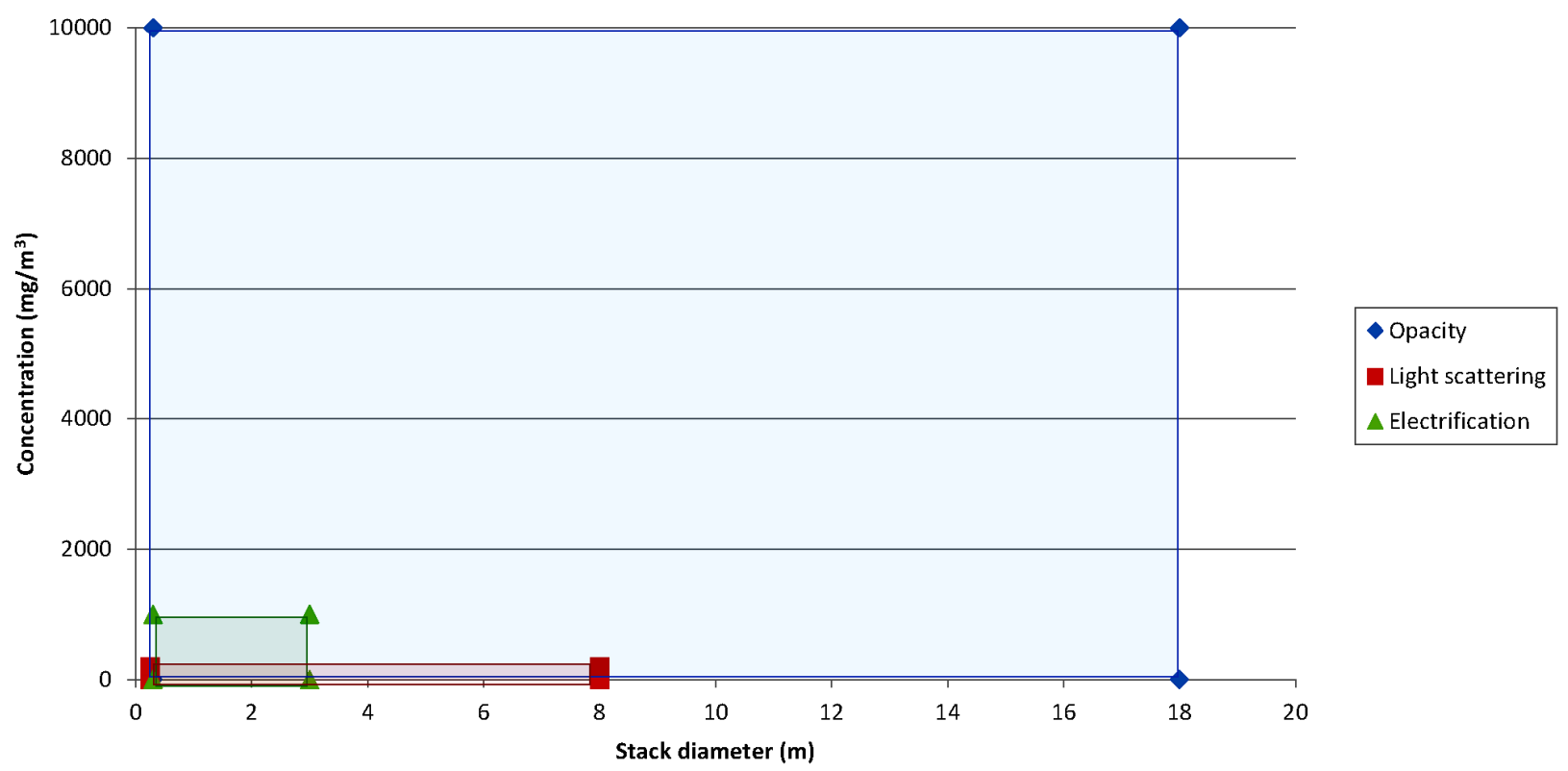

\section{Author Contributions}

All authors contributed extensively to the work presented in this paper.

\section{Nomenclature}

$\begin{array}{ll}\text { CEMS } & \text { Continuous Emission monitoring system } \\ \text { ESP } & \text { Electrostatic precipitator } \\ \text { I } & \text { Light intensity } \\ \text { Op } & \text { Opacity } \\ \text { PM } & \text { Particulate matter } \\ \text { T } & \text { Transmittance }\end{array}$

\section{Conflicts of Interest}

The authors declare no conflict of interest.

\section{References}

1. Engel-Cox, J.; Thi, N.; Oanh, K.; van Donkelaar, A.; Martin, R.V.; Zell, E. Toward the next generation of air quality monitoring: Particulate Matter. Atmos. Environ. 2013, 80, 584-590.

2. Environment Agency. Technical Guidance Note (Monitoring) M15-Monitoring PM 10 and PM 2.5; Environment Agency: Rotherham, UK, 2012; pp. 16.

3. England, G.C.; Zielinska, B.; Loos, K.; Crane, I.; Ritter, K. Characterizing PM 2.5 emission profiles for stationary sources: Comparison of traditional and dilution sampling techniques. Fuel Process. Tech. 2000, 65, 177-188. 
4. United States Environmental Protection Agency. Current Knowledge of Particulate Matter (Pm) Continuous Emission Monitoring; US Office of Air Quality: Research Triangle Park, NC, USA, 2000.

5. Otterstedta, J.E.; Geverta, S.B.; Jäåsb, S.G.; Menona, P.G. Fluid catalytic cracking of heavy (residual) oil fractions: A review. Appl. Catal. 1986, 22, 159-179.

6. Boerefijna, R.; Guddeb, N.J.; Ghadiria, M. A review of attrition of fluid cracking catalyst particles. Adv. Powder Tech. 2000, 11, 145-174.

7. Kirk, R.E.; Othmer, D.F.; Grayson, M.; Eckroth, D. Kirk-Othmer Encyclopaedia of Chemical Technology, 3rd ed; John Wiley: New York, NY, USA, 1981; p. 664.

8. Bass, J.L.; Ritter, R.E. The microstructure of fluidizable cracking catalysts. J. Mater. Sci. 1977, $12,583-594$.

9. Johnsson, F.; Breitholz, C.; Leckner, B. Solids segregation in a CFB-boiler furnace. In Fluidization IX; Fan, L.-S., Knowlton, T.M., Eds.; Engineering Foundation: New York, NY, USA, 1998; pp. 757-764.

10. Forsythe, W.L., Jr.; Hertwig, W.R. Attrition characteristics of fluid cracking catalysts-laboratory studies. Ind. Eng. Chem. 1949, 41, 1200-1206.

11. Wu, C.; Cheng, Y.; Ding, Y.; Jin, Y. CFD-DEM simulation of gas-solid reacting flows in fluid catalytic cracking (FCC) process. Chem. Eng. Sci. 2010, 65, 542-549.

12. Jiménez-García, G.; Aguilar-López, R.; Maya-Yescas, R. The fluidized-bed catalytic cracking unit building its future environment. Fuel 2011, 90, 3531-3541.

13. Schacht, J.; Courtheyn, J. ESP units realise major dust emission reduction at Total Refinery Antwerp. In Proceedings of Dust Conf 2007, International Conference, Maastricht, The Netherlands, 23-24 April 2007.

14. Bastian, R.E.; Lambert, R.H. Particulate matter continuous emission monitor test performance in a moisture-saturated flue gas. Waste Manag. 2000, 20, 369-377.

15. Keener, M.E.; Lambert, R.H.; Bastian, R.E. The effect of averaging time on compliance of a PM threshold when using continuous emission monitors. Waste Manag. 2000, 20, 379-383.

16. Dunn, J.E., Jr.; Davis, W.T.; Calcagno, J.A.; Allen, M.W. Field testing of particulate matter continuous emission monitors at the DOE Oak Ridge TSCA incinerator. Waste Manag. 2002, 22, $427-438$.

17. Chen, C.; Habert, G.; Bouzidi, Y.; Jullien, A. Environmental impact of cement production: detail of the different processes and cement plant variability evaluation. J. Clean. Prod. 2010, 18, 478-485.

18. Kalacic, I. Chronic nonspecific lung disease in cement workers. Arch. Environ. Health 1973, 26, 78-83.

19. Van Oss, H.G.; Padovani, A.C. Cement Manufacture and the Environment Part II: Environmental Challenges and Opportunities. J. Ind. Ecol. 2003, 7, 93-126.

20. Fraboulet, I.; Chaucherie, X.; Gouriou, F.; Gautier, F.; Karoski, N.; Thille, H.; Fiani, E.; Le Bihan, O. Aerosol size distribution determination from stack emissions: the case of a cement plant. In Proceedings of Dust Conf 2007, International Conference, Maastricht, The Netherlands, 23-24 April 2007.

21. Gupta, R.K.; Majumdar, D.; Trivedi, J.V.; Bhanarkar, A.D. Particulate matter and elemental emissions from a cement kiln. Fuel Proc. Tech. 2012, 104, 343-351. 
22. Kangas, R. Continuous monitoring of exhaust gas dust emissions from a steel melting shop. Filtrat. Separ. 2004, 41, 35-40.

23. Fleischandel, A.; Plattnel, T.; Lanzerstorfer, C. Efficient Reduction of PM 10/2.5 emissions at Iron Ore Sinter Plants. In Proceedings of Dust Conf 2007, International Conference, Maastricht, The Netherlands, 23-24 April 2007

24. Yao, Q.; Li, S.-Q.; Xu, H.-W.; Zhuo, J.-K.; Song, Q. Studies on formation and control of combustion particulate matter in China: A review. Energy 2010, 35, 4480-4493.

25. Meij, R.; te Winkel, B.H.; Spoelstra, H.; Erbrink, J.J. Aerosol emissions from dutch coal-fired power stations. In Proceedings of Dust Conf 2007, International Conference, Maastricht, The Netherlands, 23-24 April 2007.

26. Krutzler, T.; Böhmer, S. Dust emissions from biomass boilers in Austria. In Proceedings of Dust Conf 2007, International Conference, Maastricht, The Netherlands, 23-24 April 2007.

27. Yoo, J.-I.; Kim, K.H.; Jang, H.N.; Seo, Y.; Seok, K.S.; Hong, J.H.; Jang, M. Emission characteristics of particulate matter and heavy metals from small incinerators and boilers. Atmos. Environ. 2002, 36, 5057-5066.

28. Horne, R. Particulate emissions-Optical and other methods for continuous monitoring from a point source. In Industrial Air Pollution Monitoring, 1st ed.; Springer: Houten, The Netherlands, 1998; pp. 61-80.

29. Averdieck, W. Selection of Particulate Monitors; Technical Paper 4 (Issue 1); PCME Ltd.: St Ives, Cambridgeshire, UK, 2011; pp.8.

30. Uthe, E.E. Evaluation of an Infrared Transmissometer for Monitoring Particulate Mass Concentrations of Emissions from Stationary Sources. J. Air Poll. Control Assoc. 1980, 30, 382-386.

31. Conner, W.D. Measurement of Opacity and Mass Concentration of Particulate Emissions by Transmissometry; EPA 650/2-74-128; National Environmental Research Center, Office of Research and Development, U.S. Environmental Protection Agency: Research Triangle Park, NC, USA, 1974.

32. Conner, W.D.; Knapp, K.T.; Nader, J.S. Applicability of Transmissometers to Opacity Measurement of Emissions-Oil-fired Power Plants and Portland Cement Plants; EPA 600/2-79-188; U.S. Environmental Protection Agency: Washington, DC, USA, 2002.

33. PCME. Available online: http://www.pcme.com/ (accessed on 28 May 2014).

34. Durag Group. Available online: http://www.durag.com/d_r_290.asp (accessed on 28 May 2014).

35. Land Ametek Process and Analytical Instruments. Available online: http://www.landinst.com (accessed on 28 May 2014).

36. Sick Sensor Intelligence. Available online: http:/www.sick.com/group/en/home/products/ (accessed on 28 May 2014).

37. McCartney, E.J. Optics of the Atmosphere: Scattering by Molecules and Particles; John Wiley and Sons, Inc.: New York, NY, USA, 1976; p. 421.

38. Redmond, H.E.; Dial, K.D.; Thompson, J.E. Light scattering and absorption by wind blown dust: Theory, measurement, and recent data. Aeolian Res. 2010, 2, 5-26.

39. Sigrist Process Photometer. Available online: http://www.photometer.com/en/index.html (accessed on 30 June 2014). 
40. Matsusaka, S.; Maruyama, H.; Matsuyama, T.; Ghadiri, M. Triboelectric charging of powders: A review. J. Electrostatics 2004, 62, 277-290.

41. Environment SA. Available online: http://www.environnement-sa.com/products-page/ (accessed on 28 May 2014).

42. Averdieck, W. Electrodynamic Technology for Particulate Monitoring; Technical Paper 13 (Issue 12); PCME Ltd.: St Ives, Cambridgeshire, UK, 1999; pp.5.

43. Dr. Födisch Umweltmesstechnik AG. Available online: http://www.foedisch.de/en/products/ devices/dust-measurement-devices/r-dust-measurement-devices.html (accessed on 28 May 2014).

44. Peeler, J.W.; Jahnke, J.A. Handbook: Continuous Emission Monitoring Systems for Non-Criteria Pollutants; EPA 625/R-97/001; U.S. Environmental Protection Agency: Washington, DC, USA, 1997.

(C) 2014 by the authors; licensee MDPI, Basel, Switzerland. This article is an open access article distributed under the terms and conditions of the Creative Commons Attribution license (http://creativecommons.org/licenses/by/3.0/). 